\title{
Action-Guidance: An Action Research Project for the Application of Informing Science in Educational and Vocational Guidance
}

\author{
Antonio Cartelli \\ University of Cassino, Cassino (FR), Italy
}

\author{
cartan@unicas.it
}

\begin{abstract}
After a short introduction that describes the author's interest in educational and vocational guidance, this paper reports on the psychological and pedagogical contributions to the analysis of the phenomenon. The limits of the above approaches are then analyzed and the need for the monitoring of the students' cognitive, relational and affective spheres is explained.

The last section of the paper focuses on monitoring of vocational and educational guidance, and offers a proposal to hit this target. In the author's opinion, the analysis of the guidance processes, its further control and the planning of new actions can only be obtained with the joint adoption of the action research strategies, of the use of the ICT, and of a special Information System.
\end{abstract}

As a consequence of the above hypothesis, Informing Science appears as the transdiscipline that can play a relevant role in educational and vocational guidance.

Keywords: Educational guidance, Vocational guidance, Information System, Informing Science, Psychology, Pedagogy, Action Research.

\section{Introduction}

Many recent research studies, especially the OECD and the UNESCO analyses of secondary education's status and evolution, show that many students do not graduate from high school. In Italy, as the most recent yearly reports of the Italian Ministry of Education show, the phenomenon is much more pronounced, in spite of the large number of innovations in curricula and school organization that public institutions carried out during the last years. Furthermore, the percentage of the students leaving the Italian schools before graduation is among the highest in the European countries and, as comparison with the other Western countries shows, among the highest ones among the developed countries.

The size of the problem of students' departure recently induced the Italian Ministry of Education to start some projects to uncover the reasons students drop out of school and to suggest interventions to give better guidance to the same students in their professional and educational choices.

Material published as part of this journal, either on-line or in print, is copyrighted by Informing Science. Permission to make digital or paper copy of part or all of these works for personal or classroom use is granted without fee provided that the copies are not made or distributed for profit or commercial advantage AND that copies 1) bear this notice in full and 2) give the full citation on the first page. It is permissible to abstract these works so long as credit is given. To copy in all other cases or to republish or to post on a server or to redistribute to lists requires specific permission from the publisher at Publisher@InformingScience.org
The $2^{\text {nd }}$ level Master course for "Educational Guidance Agents", organized from a consortium of Italian Universities and devoted to the High School teachers of the Lazio Region in Central Italy, is one among the various initiatives funded by the Italian $\mathrm{Na}$ tional and Regional Authorities to hit 
the above target.

As this paper shows, the involvement of the author as a professor within that Master course and the discussions he held with the teachers taking part at the lectures on the main features of this guidance process gradually led to the hypothesis involving the application of Action Research strategies and of Informing Science ideas and, especially, to the adoption of an Information System for the monitoring of the educational and vocational guidance action and for the building of a community of study and research who could help students in better living within the School and in making conscious choices about their school and professional careers.

\section{Educational and Vocational Guidance}

Educational and Vocational Guidance are often seen as two different aspects of the more general guidance process that makes people able to autonomously choose their course of study or their future work life. The complexity of the guidance process naturally involves the competences and contributions pertaining to various disciplines, such as psychology, sociology, anthropology and pedagogy, and contributes to looking at the guidance action as an interdisciplinary field of investigation. The suggestions emerging from the above disciplines agree on the main trait and aim (at least in the school) of that process: that is to enable students to steer themselves by means of a project of life that they build together with their teachers and families (Mancinelli, 1999). Among the various disciplines interested in the guidance process, the ones this author will analyze in a greater detail will be psychology and pedagogy, because of the high number of experiences concerning them that are reported in scientific literature and for the importance they will have in what follows. It is well known in fact that psychology mainly looks at the individual evolution and at the interventions to be made on the subjects for a successful guidance process; on the other hand, pedagogy and, especially, didactics look at the whole educational process and at its management for a global intervention on the students' guidance and for making them develop selfassessment and decision skills together with good evaluation instruments.

\section{Educational Guidance and Psychology}

From a psychological point of view it is well known that the guidance process aims to lead the students to develop design and planning skills and that two different ways of intervention can be used to hit this target (Gibson \& Mitchell, 1999):

- the self-guidance action, i.e. the skills and the behaviors that the subjects have to carry out for facing the problems they meet in school, at work or in their everyday life, and that are induced from the psycho-sociological processes,

- the professional interventions that various kinds of agents and professionals can carry out to help people in the development of their guidance skills.

If many studies confirm that the above actions are the ones inducing self-guidance skills in the students, it is also true that they help people in self-managing their personal and professional life. The hypothesis subtending the above assertion assigns to the development of planning skills and of responsibility in decision making the role of the primary elements for the reaching of a satisfying self-fulfillment and for a fruitful introduction in everyday life and society.

It has to be noted that if there is a general agreement on the above common targets, several models of educational and vocational guidance have been developed over time, mostly devoted to special categories of people or separately to students and workers.

The global-interdisciplinary approach, which is based on the theoretic contributions and on the research methods coming mainly from psychology but also from different disciplines, is today commonly widespread and the guidance process is no more analyzed in a reductive and mono- 
disciplinary way but in its whole complexity by means of a network of services and agents sharing information.

The above approach suggests constant observation of the following features when a guidance intervention is planned (Cowie \& Sharp, 1996):

- the knowledge of the factors involved in the guidance process,

- the analysis of the image the students have of themselves and of the social context they live in,

- the empowerment of the students' individual resources,

- the collection and organization of the information required to come to a decision,

- the development of the students' planning and decision skills,

- the use of the information sources concerning the society and the work market,

- the acquisition of the students' right behaviors for reaching the predefined targets.

The instruments that teachers and counselors most commonly have for acquiring the information they need for the development of a good guidance action are the usual ones: tests, questionnaires and interviews.

The phases of school life requiring the largest use of the above instruments for planning guidance interventions are the transition ones, i.e. the ones marking the passage from a level of school to another one or just before the end of compulsory school.

The evaluation of the guidance action occurs by means of the evaluation of:

- the guidance program, i.e. the judgment on the various aspects of the program, its interaction with the school curriculum, the quality and quantity of contributions etc.

- the people involved in the guidance program: the environment, the family, the schoolteachers, the experts, the psycho-pedagogical team etc.

- the results of the guidance action in the short, medium and long time, i.e. how the students achieve the objectives of the program and develop over time the features of the program and its targets.

\section{Educational Guidance and Didactics}

From a pedagogical point of view the guidance process is an integral part of the educational process because the development of self-guidance and decision making skills are among the natural targets of individuals' growth and evolution during their lifetime.

Many pedagogical theories followed one another over time; some putting more and some less attention to the guidance process. During last decades the autonomy that didactics gained with respect to pedagogy, as the discipline of the knowledge communication process, assigned a greater and greater importance to the guidance action, as a fundamental part of the teaching learning process.

First of all it has to be noted that the didactics' point of view assigns a great role in the guidance action to the knowledge, the abilities and the skills that the students have to obtain for better facing the changes imposed from today's life, and many scholars agree on the following features for the cognition the students have to acquire (Domenici, 2001):

- $\quad$ to be meaningful, i.e. to involve the students in the learning process so that new knowledge correctly inserts on previous knowledge, 
- to be systematic, i.e. to be an organic and coherent set within which each element has a sense,

- to be stable, i.e. to persist in the time and to make easy the use of the semantic memory with respect to the mechanic one,

- to be basic, not only in a more traditional meaning (phylo-genetically) but also in its modernity (to induce the revision of a discipline),

- to induce a capitalization of knowledge for its property of penetrating and handling further knowledge.

Secondly the influence that the introduction of the methods and techniques of organization theory had on the didactic process and on teaching has to be considered. In fact, in the late "70s theory assigned a great relevance to the planning and design of study curricula in the school, and the didactic action was seen as a cyclic process marked by the following phases: a) the specification of the cognitive targets the students had to hit, b) the planning and design of the teaching work, c) the evaluation of the teaching efficacy, d) the definition of the feed-back actions to be carried out for helping students in overcoming their difficulties and for finding new targets in a new cyclic process (Nicholls \& Nicholls, 1983).

In Italy the introduction of the above elements of innovation in the organization of the first years of High School (i.e. the last three years of compulsory school) induced the Ministry of Education to propose a special evaluation instrument (i.e. a form) to be adopted nation wide; this document, very similar for its structure to a case history, changed its structure over time assigning more or less space to different sections (i.e. the parts describing the planned teaching, the answers of the students, the observations of the teachers and the connections among themselves), but it is currently still the most important document (and the only official one) that the students and the families have for the analysis of the didactic process in the school (at least in the last years of the Italian compulsory school).

Furthermore, many scholars assigned a great importance to the use of metacognitive strategies for the development of the students' self-guidance skills (Damiano, 1994). This hypothesis implies the adoption of metacognitive strategies in teaching, because it is based on the assumption that thinking about cognitive processes and using concept maps for the representation of the phenomena and of the knowledge construction can help the students in the development of planning skills and meaningful learning.

The latest didactic proposals for diachronic educational guidance concern the use of a set of new strategies that are well summarized in the modular didactic approach (Domenici, 2001). The teachers adopting this theoretical model have to use a global approach in the analysis of the problems they submit to their students and have to propose each new topic in an interdisciplinary perspective.

The evaluation of the didactic process, independently from the theoretical approach that the teachers can adopt is almost formal (at least in Italy); it is based on the correctness of the project the teacher makes and on the adherence of the everyday class work with the planned teaching. Sometimes (yearly in the most favorable situations) cognitive tests concerning reading, writing and calculation skills are adopted on a local, regional or national basis and a screening of the school situation is made to compare temporal and spatial situations and results.

\section{Pros and Cons in the Above Perspectives}

The above approaches undoubtedly contributed in the definition of the terms and situations marking an educational and vocational guidance intervention both in the case of an individual and in the case of a huge crowd. 
Thanks to the psychological research we have a lot of tests and questionnaires and many examples of interviews that can be used for the analysis of the main features of a subject in his/her affective, relational and cognitive aspects. The data obtained from the answers to the above instruments can be very useful for the design of a guidance action devoted to the modification of the student's expectations and of his/her life styles and in the development of the strategies to be adopted in the decision making processes.

In didactics, on the other hand, the various teaching strategies described above can be successfully applied all together or separately from the teachers on the basis of the data emerging from the analysis of their classes and, as the results of the experiences carried out up to now show, they can contribute to the students' acquisition of a meaningful learning.

In both cases it seems clear, in the author's opinion, that we are still in an experimental stage and that it is very difficult to find elements leading to any kind of final perspective or, what's more, to the proposal of a unique and well defined and structured educational guidance.

Elements supporting the above assertion can be found in the results of some experiences recently carried out in both disciplines.

In psychology two areas of investigation that produced very interesting results are: the students' acceptance of the results of the tests' answers, and the analyses of some follow-up studies concerning the correlation between students' scores and their success in further studies (Boncori \& Boncori, 2002). In the first case it has been shown that students tend to accept the reports of the psychological tests only if they empower a positive self-opinion, otherwise they tend to reject them. The follow-up analysis on three different sets of High School students (which were obtained by grouping the students on the basis of the mean scores they got at the cognitive tests during the years of their permanence in the High School) showed that: a) there is no correlation between the above student sets and the scores they got at the school leaving examinations, $b$ ) there is only a little correlation between the above student sets and their academic success (in terms of the number of examinations they got at the University), c) the most talented students got the highest number of examinations at the University.

In the didactics case the successfulness of the school teaching has been measured by means of the results of the cognitive investigations that were carried out on a national or international basis (IEA, IEA-SISS, IEA-SAL), all showing the inadequacy of the school system in the achievement of the cognitive targets (at least in Italy):

- the positive results decrease with the increase of the school level,

- today's good scores, with respect to some decades ago, are no long decreasing while passing from the North to the South of the country, but are irregularly distributed all over the nation,

- the same good results no longer depend on the students' social status but are mostly influenced by the mothers' degrees (it is especially true in the case of the human sciences).

The above elements show the difficulties in defining and characterizing an educational and vocational guidance program. Consequently, it is useful, in the author's opinion, to list some of the elements that are usually considered responsible for the above difficulties (Domenici, 2001):

- the surveying times usually adopted when an inquiry is carried out (i.e. questionnaires and test are proposed at the beginning and at the end of the processes to be investigated),

- the small number of persons involved in concrete guidance actions with respect to the staff involved in the educational and vocational guidance programs, which makes it difficult to apply the results of an experience to more general situations,

- the expense for planning and carrying out a nationwide guidance action, 
- the overall rigidity of the school system (at least in Italy), which does not assure the students an easy passage from a given type of school to another one (i.e. from a class of the Compulsory school to the corresponding one of the Technical school or of the Liceo and vice versa) when it is needed,

- the strictly bureaucratic features of the assessment tests, which only rarely can be used for planning guidance actions that can help the students with the worst scores.

\section{The Action Research and Informing Science in the Action-Guidance Project}

In the above section, on the basis of the analysis of the Italian situation, a list of the most common problems that an educational or vocational guidance action has to face and overcome was reported. However, it is not improbable to hypothesize that in other Western countries the same or very similar problems could happen, as the number of the experiences and projects that followed one another in USA and UK seem to confirm (Morris, 1996, Starr, 1996).

The elements that, in the author's opinion, can produce the best results or give more efficacy to the guidance action, can help the scholars and the researchers in the analysis of the phenomenon, and can lead the students, their families and the teachers to overcome the problems reported above, are the following ones:

1. the methods and the instruments of the disciplines involved in the analysis of the students' features and environment need a closer alignment. In other words the planning of the school work, mostly pertaining to didactics, has to consider the guidance action as a part of the teaching-learning process (i.e. special jobs helping students in the development of their selfguidance skills have to be planned in everyday school work together with discipline topics). Furthermore, the analysis of the students' evolution and their reactions to the planned interventions, usually analyzed with psychological techniques and strategies, have to enter in the planning of the class work.

2. the action research strategies have to replace the hypothetical-deductive models of phenomena interpretation, which are usually adopted in the psychological and didactical approaches to guidance actions.

3. a real and effective continuous monitoring of the educational processes and of the actors involved in that process has to support the evaluation and assessment of the teaching-learning processes and the analysis of the students' relational and affective spheres.

As regards the first item, it has to be said that it is the natural consequence of the remarks concerning the pros and cons in the adoption of the purely psychological or purely didactic approaches to the guidance process. Furthermore it naturally leads to the adoption of a diachroniccontinuous evaluation of the behaviors and of the processes involved in the guidance action, more than to a synchronous-ending evaluation of the same elements. In this way, in the author's opinion, the situations needing the planning of support interventions will be more easily found and much of students' troubles and loss can be prevented. It is quite obvious that this target can be hit only if a strong collaboration among researchers, experts, teachers, students and families is established.

The second item is strictly related to the first one because of the features of the action research inquiry method. It is well known that the action research scientist is fully immersed in the reality he/she's studying and that the modifications he/she can induce in the phenomenon under investigation are an integral part of this study and research method (Scurati \& Zanniello, 1993). On the other hand, one of the most prevalent action research descriptions (Susman \& Evered, 1978), de- 
tails a five phase, cyclic process that, in the author's opinion, can guarantee the best development of every guidance process (together with its analysis and description). The five identifiable phases that can be iterated are: 1. diagnosing, 2.action planning, 3. action taking, 4. evaluating, and 5. specifying learning. It has also to be noted that the use of the action research strategies involves a closer and wider communication among the people involved in the inquiry and that the researchers must pay close attention to ethical considerations in the conduct of their work. Richard Winter (1996), for example, lists a number of the principles that every action research inquiry has to observe:

- make sure that the relevant persons, committees and authorities have been consulted, and that the principles guiding the work are accepted in advance by all,

- all participants must be allowed to influence the work, and the wishes of those who do not wish to participate must be respected,

- the development of the work must remain visible and open to suggestions from others,

- permission must be obtained before making observations or examining documents produced for other purposes,

- descriptions of others' work and points of view must be negotiated with those concerned before being published,

- $\quad$ the researcher must accept responsibility for maintaining confidentiality.

The above elements are, obviously, an integral part of the project reported here, but, as already stated, there is also the need for a continuous monitoring of the guidance actions and of the teaching learning processes more in general, i.e. the third innovative element in the author's proposal.

It has to be noted that the experience of recent years, with the use of complex paper supports (at least in Italy where case histories have been adopted for the description of the students features), has shown that: a) teachers can spend a great part of their time in compiling those forms rather than in teaching planning and analysis and $b$ ) the same forms can be useless for a vocational and educational guidance devoted to all the students in a school. The required monitoring can then be achieved, in the author's opinion, only with the help of the ICT (Information and Communication Technologies) and especially with the joint contribution of the following two elements: 1) the use of data storage and retrieving strategies or, what is better, the use of data mining methods and 2) the adoption of Web technologies. It is well known that a simple PC, linked to Internet and equipped with a multiple access and time sharing operating system (i.e. UNIX like), and with a Web server interfaced with a RDBMS (Relational Data Base Management System), can easily store every kind of information coming from everywhere: the students' homes, the schools, and the counselors's and scholars' centers. (It can be hypothesized that School time can be set aside to allow students or families that do not have access to an Internet connection to input the required data.)

On the other hand, it has to be noted that many experiences concerning action research and ICT have been recently carried out all over the world. One among them has been proposed in Italy by Antonio Calvani, who attributed the name of on-line action research to the set of methods and strategies he outlined (Calvani, 2000). The main traits of his hypotheses, integrating action research and Internet services, are: a) the building up of new models of didactic innovation that can take possession of the hypotheses of phenomenological and hermeneutical theories, and b) the validation of the results of the didactic innovation that are usually deformed by personal interpretation when qualitative methods are adopted. In other words, e-mails, messages in electronic blackboards and all other communication channels activated by the Internet can be used to guarantee the extension of the meaning of community (virtual community) and can store all the in- 
formation concerning the phenomenon under observation, so leading to a continuous monitoring and validation of the process under investigation.

With respect to Calvani's hypotheses this paper suggests an innovative element strongly based on the adoption of the social statistics strategies. In the author's opinion, the simple storage and retrieving of information in the analysis of social phenomena and especially in the case of the guidance actions, is not sufficient to ensure an efficient planning of the interventions to be done. The application of the social statistic methods to the data stored in the Information System can lead, on the other hand, to the discovery of new features in the population under observation, which usually behave differently from each individual (i.e. the usual statistical parameters, such as mean value, range, standard deviation, asymmetry, kurtosis, and so forth, trace a profile of the population that doesn't correspond to the ones of the subjects belonging to the same universe). Furthermore, the comparison of the individual's features with the global ones can help all the actors involved in the analysis of the phenomenon in finding anomalies and unusual behaviors that can require further investigations and the planning of new researches or interventions.

In the author's opinion, the instrument that can make real the above hypothesis is an Information System with the following features: a) different accesses for the various users of the system, b) guaranteed security and privacy for each user, c) easy input of the information concerning the students' aspects and the environmental data (for example by means of Web forms that can be accessed from everywhere: school, home etc.) d) easy access, depending on the assigned permission, to the statistical information, such as historical series of the individual data or the same data coming from groups of them or from the whole population under observation, e) easy production of the individual and global variables' distributions and specification of the subjects with anomalous or extreme values in the distribution, $\mathrm{f}$ ) strong presence of communication instruments, such as e-mail services, electronic blackboards, chat, and so on.

An Information System with the above features is at the basis of the action-guidance project the author is proposing to the academic staff of his Faculty and University, to the schools of the local district, to the school administration offices and to local public administrators, to revise the usual strategies which are currently adopted in the management of the educational and vocational guidance. If the project will be adopted the educational and vocational guidance will become an event-driven process within which students' expectations, students' scores and evaluations, environmental data and school data will be the phenomena to be observed and to be translated in indices describing the environment within which the guidance action will be planned from families, teachers and guidance staff.

The statistical analysis of the data stored in the Information System will give to the people involved in the project:

1. the change over time of the features of a single student (by means of indices describing well defined kinds of behaviors and of learning styles),

2. the change over time of the features of the same students' groups, i.e. the classes and the whole schools,

3. the change in the space of the features of different students' groups, that is how different environments can modify the evolution of identical or very similar guidance actions' plans applied to them.

Perhaps the observed phenomena will require new indices to be observed and analyzed. If so, these new indices will be made an integral part of the Information System. What has been described represents a real application of the Action Research methods. 
It has to be noted that the above hypotheses have relevant consequences for the disciplines involved in the analysis of the teaching-learning process and for educational and vocational guidance because they assign a special role to the Informing Science as the discipline that can "provide its clientele information in a form, format and schedule that maximizes its effectiveness" (Cohen, 1999). The clients are now of two kinds: on one hand there are the students, their families, the teachers and the institutions, i.e. the people involved in the guidance process; on another hand there are the scholars and the researchers of the disciplines usually involved in the analysis of the guidance process and more generally in the study of the teaching-learning process: Technologies of education, Didactics, Curriculum and Organization Theories, Psychology, Sociology and Philosophy. Figure 1 shows, as already happened for the model that the author hypothesized in the analysis of the teaching-learning process (Cartelli, 2003), the connections existing among the various disciplines. In other words the action-guidance project will assign to the Informing Science the role of an intermediary between the guidance process and the disciplines that mainly study this process.

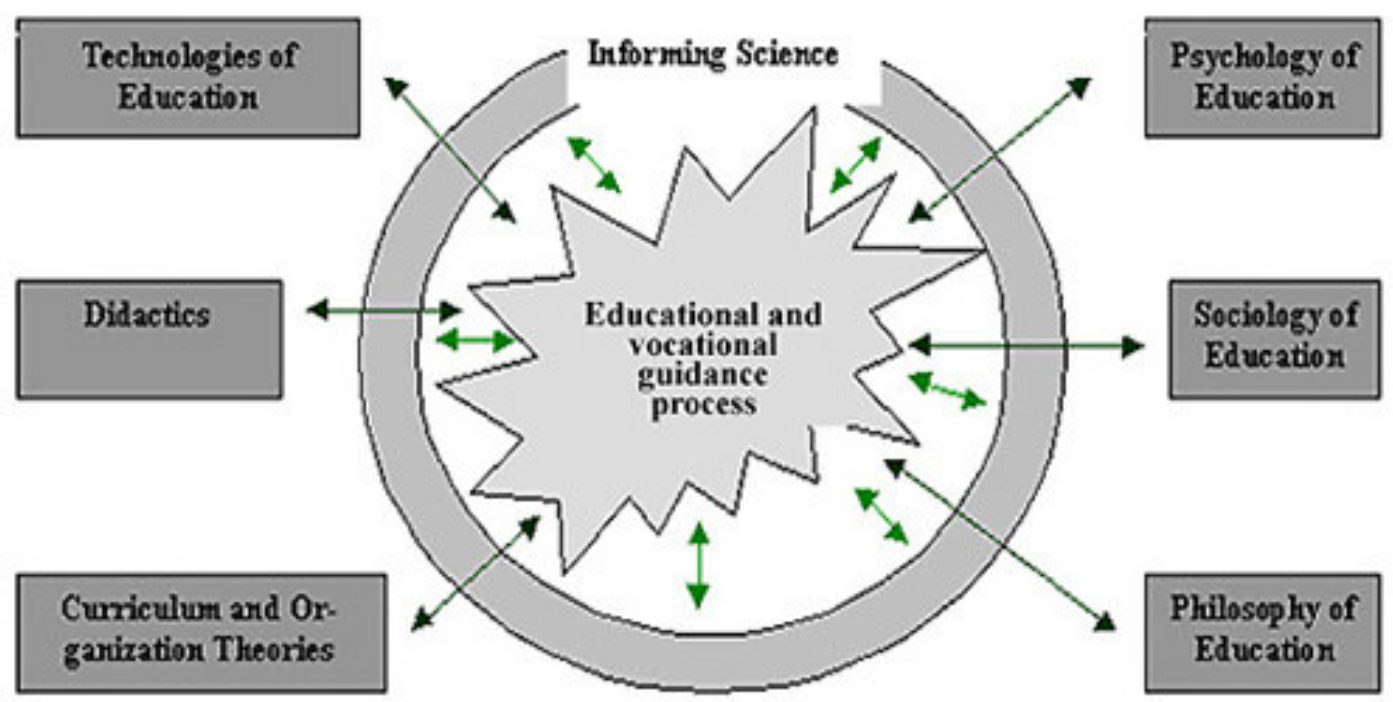

Fig. 1 - The Informing Science and the vocational and educational guidance process

\section{Conclusions}

It is quite obvious that the idea of the action-guidance project still requires a great work before becoming something concrete. First of all the identifying of the right instruments to be implemented in the Information System has to be made, i.e. the questions to be asked to the students, to the teachers and to the families, and how they have to be posed. Secondly a good analysis of the permissions each kind of user has to be granted for the access to information is needed. And last, the elements to be used as indices for the analysis of the data stored in the on-line data base has to be made and the transformation from an information retrieving system to a knowledge management system has to be planned, i.e. the data mining techniques to be adopted for the analysis of the stored data have to be designed.

After having solved the above problems the level of detail of the universe to be investigated has to be found (i.e. school, district etc.) and the best software and hardware instruments have to be chosen. For the last elements, in the author's opinion, a good help can come from Open Source software freely available on the Net. It will be very useful for carrying out a first prototype of the 
System and for the test of the correctness of the ideas in the project itself, but it could be used also for a final version of the Information System.

\section{References}

Boncori, L., \& Boncori, G. (2002). L'Orientamento. Rome: Carocci.

Calvani, A. (2000). Ricerca azione on-line: Nuovi modelli per l'innovazione e la sperimentazione educativa. Retrieved January 21, 2004, from http://www.educational.rai.it/corsiformazione/autonomia/mappa/rtf/29_ris_02b.rtf

Cartelli, A. (2003). Misinforming, misunderstanding, misconceptions: What informing science can do. In E. Cohen and E. Boyd (Eds.), Proceedings of 2003 IS + IT Education Conference, Pori (Finland), pp. 1259-1273.

Cohen, E. (1999). Reconceptualizing information systems as a field of the transdiscipline informing science: From ugly duckling to swan. Journal of Computing and Information Technology, 7 (3), 213-219. Retrieved from http://informingscience.org/WhatIS.htm

Cowie, H., \& Sharp, S. (Eds.). (1996). Peer counselling in schools: A time to listen. London: David Fulton.

Damiano, E. (Ed.). (1994). Insegnare con i concetti. Turin: SEI.

Domenici, G. (2001). Manuale dell'orientamento e della didattica modulare. Bari: Laterza.

Gibson, R. L., \& Mitchell, M. H. (1999). Introduction to Counselling and Guidance. Upper Saddle River, NJ: Prentice Hall.

Mancinelli, M. R. (1999). L'orientamento in pratica. Guida metodologica per insegnati di scuola secondaria superiore, orientatori, psicologi. Milan: Alpha Test.

Morris, M. (Ed.). (1996). Careers education and guidance provision for 13 and 14 years old-Report. Slough: NFER.

Nicholls A., \& Nicholls, H. (1983). Guida pratica all'elaborazione di un curricolo. Milan: Feltrinelli.

Scurati, C., \& Zanniello G. (Eds.). (1993). La ricerca azione. Naples: Tecnodid.

Starr, M. F. (1996). Comprehensive guidance and systematic education and career planning: Why a K-12 approach? Journal of Career Development, 23, 9-22.

Susman, G., \& Evered, R. (1978). An assessment of the scientific merits of action research. Administrative Science Quarterly, 23 (4), 582-603.

Winter, R. (1996). Some principles and procedures for the conduct of action research. In Ortrun ZuberSkerritt (Ed.), New Directions in Action Research (pp.13-27). London: Falmer Press.

\section{Biography}

Antonio Cartelli is a researcher of Didactics and manages the Centre for ICT and on line teaching in the Faculty of Humanities at the University of Cassino - Italy. Among his interests are: misconceptions, mental schemes, Information Systems for research and teaching, Web Technologies in teaching research and their everyday application for the improvement of teaching and learning. He is also the author of many papers concerning the themes he is interested in. 